faculty is making proposals to strengthen it and bind it ever more closely to its parent body, the Royal College of Surgeons.

DEREK SEEL

Faculty of Dental Surgery

Roval College of Surgeons of England,

London WC2A $3 \mathrm{PN}$

1 Delamothe T. Hunterian Institute and dental research. Br. Med 7 1989:299:757. 23 September

\title{
Mumps, measles, and rubella vaccination and encephalitis
}

SIR,-Dr Suzanne Crowley and colleagues describe the onset of encephalitis in a 14 month old girl 27 days after she was given mumps, measles, and rubella vaccine. In this case it should be emphasised that there is no proof that the encephalitis was due to the mumps component of the vaccine. The fourfold rise in mumps $S$ titre could simply reflect successful immunisation. In Canada, where there have been several reports of meningitis arising within four weeks of giving mumps, measles, and rubella vaccine, mumps virus was isolated from the cerebrospinal fluid in all cases, although it was not possible to prove the origin of the viruses

After over one million doses of mumps, measles, and rubella vaccine it would be surprising if the occasional neurological reaction did not occur, but it would be a pity if current initiatives to improve the protection of British children from measles, mumps, and rubella were to be affected adversely by the publication of such a speculative case report. Nevertheless, it is most important that such cases are fully documented and reported on the "yellow card" system to the Committee on Safety of Medicines so that the benefits and risks of new vaccines can be kept in perspective. Experience to date indicates that the frequency of central nervous system complications after mumps vaccination is lower than the background incidence in the normal population. It is also worth emphasising that this patient and the Canadian patients recovered completely from the encephalitis.

A G M CAMPBELL.

Chairman

Joint Committee on

Vaccination and Immunisation

Department of Child Health

University of Aberdeen,

Aberdeen $A B 92 Z D$

1 Crowley S, Al-Jawad ST, Kovar IZ. Mumps, measles and rubella vaccination and encephalitis. Br Med 7 1989;299:660. September

2 Hockin JC. Mumps meningitis, possiblv vaccine related Ontario. Canada Diseases Weekly Report 1988;14:209-11.

\section{Follicular stimulation: is it safe?}

SIR,-Drs S Fishel and P Jackson raise the question of causality of follicular stimulation in the genesis of ovarian cancer.' Although they emphasise that there is no direct evidence to support their hypothesis, their discussion is incomplete.

Ovarian cancer is a common malignancy in women. ${ }^{2}$ Particularly, women with low parity or infertility, or both, are at a higher risk of developing ovarian cancer. Nulligravidas present twice the risk of developing malignant ovarian tumours than women who have been pregnant." A silent ovarian carcinoma was found in six out of 571 patients undergoing microsurgery for infertility, compared with only one of 5806 patients undergoing non-specific abdominal surgery (a crude relative risk of $62,95 \%$ confidence interval 7 to 514). ${ }^{+}$This sampling bias should be taken into account when analysing the three case reports of ovarian cancer during induction of ovulation quoted by Drs Fishel and Jackson.

The question was raised as to whether pharmacological follicular stimulation might modify the prevalence of ovarian carcinomas. In animals, experimental ovarian tumours generated by continuous high gonadotrophin levels originate from the stromal cells of the ovary'; they therefore are not a relevant model of human ovarian neoplasms, which are mostly of epithelial origin." Luteinising hormone receptors were found in only a quarter of human malignant ovarian cancers, and, moreover, these cancers contained fewer luteinising hormone receptors than did normal ovarian tissue, which might represent normal ovarian tissue trapped between cancer cells. ${ }^{2} \mathrm{Al}-$ though it was functional, the adenylate-cyclase system of human epithelial ovarian cancer cells could not be stimulated by either follicle stimulating hormone or luteinising hormone, indicating that ovarian cancers were not target tissues for gonadotrophins.

Oestrogen secretion is increased by gonadotrophins, but there is much evidence to indicate that steroids have a protective action against ovarian cancer. ${ }^{2}$ Several epidemiological studies do not support a hypothesis of ovarian tumours induced by gonadotrophin. ${ }^{26}$ Mortality due to ovarian cancer levels off after the menopause, at a time when gonadotrophin levels are high and when mortality from epithelial cancers not dependent on hormones continues to increase. 6 "

Therefore, several arguments indicate that gonadotrophins are unlikely to cause ovarian malignancies. As it cannot, however, be totally ruled out that follicular stimulation might activate certain types of pre-existing ovarian cancers, and in view of the relatively high risk for infertile women of spontaneously presenting with ovarian cancer, the need for careful clinical evaluation with ultrasonic ${ }^{9}$ or other modern imaging techniques before and during medical treatment of infertility must be emphasised.

K BESSEGHIR A ESHKOI

\section{Ares-Serono,}

CH 1202 Geneva,

Switzerland

P BRINSDEN

Bourn Hallam Infertility Centre, R G EDWARDS

Bourn,

Cambridge CB3 7TR

1 Fishel S, Jackson P. Follicular stimulation for high tech pregnancies: are we playing it safe? Br Med f 1989;299:309-11. (29 July

2 Heintz AP, Hacker NF, Lagasse LD. Epidemiology and etiology of ovarian cancer: a review. Obstet Gynecol 1985;66:127-35.

3 Scott JS. How to induce ovarian cancer: and how not to. Br.Med $\mathcal{f}$ 1984:289:781.

4 Lais CW, Williams TJ, Gaffey TA. Prevalence of ovarian cancer found at the time of infertility microsurgery. Fertil Steri 1988:49:551-3.

5 Cramer DW, Welch WR. Determinants of ovarian cancer risk. II. Inferences regarding pathogenesis. f $N C I$ 1983;71:717-21. 6 Mohle J, Whittemore A, Pike M, Darby S. Gonadotrophins and ovarian cancer risk. $7 \mathrm{NCl}$ 1985;75:178-80.

Rajaniemi H, Kauppila A, Rönnberg L, Selander K, Pystynen P. LH(hCG) receptor in benign and malignant tumors of human ovary. Acta Obstet Gynecol Scand [S uppl] 1981;101:83-6.

8 Graves PE, Surwit EA, Davis JR, Stouffer RL. Adenylate cyclase in human ovarian cells: sensitivity to gonadotrophins and nonhormonal activators. Am f Obstet Gynecol 1985:153: $877-82$.

9 Rodriguez MH, Platt LD, Medeavis AL, Lacarra M, Lobo $\mathrm{RA}$. The use of transvaginal sonography for evaluation of postmenopausal ovarian size and morphology. Am f Obstet postmenopausal ovarian

SIR, - Drs R Kulkarni and J M McGarry' state that the warning of Drs S Fishel and P Jackson ${ }^{2}$ about the possible dangers of superovulation for assisted conception is correct and describe a single case of gynaecological tumour following treatment with antioestrogens. Four other case reports of either ovarian or breast cancer in association with ovarian follicular stimulation have been published, ${ }^{3.6}$ but though the effect of such treatment on the inci- dence of such cancers must be carefully considered we think that the question can be answered only by prospective studies with carefully selected control groups rather than by a steady stream of case reports. Even if an association were found it would not necessarily indicate an effect of ovarian stimulation; indeed, a more likely explanation would be that an underlying ovulatory disorder or simply the absence of pregnancy predisposes to gynaecological cancer. There are data showing that women with anovulatory infertility have five to six times the risk of developing premenopausal and postmenopausal breast cancer. ${ }^{7}$ In addition, polycystic ovarian disease, the commonest cause of anovulation, ${ }^{4}$ increases the risk of endometrial cancer, "and Babaknia and colleagues found an excess of ovarian neoplasms in 181 consecutive patients with SteinLeventhal syndrome attending their clinic, many of whom presented before the advent of treatment to induce ovulation.

Clearly, breast and pelvic tumours will in any case arise during or shortly after ovarian stimulation as a matter of chance alone. If follicular stimulation were to predispose to epithelial malig. nancies of the ovary, endometrium, and breast the increasing and widespread use of such treatment over the past 20 years would have been expected to generate far more than the small number of case reports that have been made. The reporting of single cases or small series tends to create false impressions and may lead to unnecessary anxiety for patients and doctors alike.

Any reluctance to prescribe such treatments as the result of such fears would deprive many women not only of the joys of motherhood but of the apparent protection that pregnancy and lactation give against developing malignant breast tumours."

ROBERT FOX PETER WARDLE

Department of Obstetrics and Gynaecology, Bristol Maternity Hospital. Bristol BS2 8EG

1 Kulkarni R, McGarry JM. Follicular stimulation and ovaria cancer. Br.Med f 1989;299:740. (16 September.

2 Fishel S, Jackson P. Follicular stimulation for high tech pregnancies: are we playing it safe? Br Med $\mathcal{F}$ 1989;299. 309-11. (29 July

3 Atlas M, Merczer J. Massive hyperstimulation and borderline carcinoma of the ovary. A possible association. Acta Obstet Gynecol Scand 1982:61:261-3.

+ Bamford IM, Steele SJ. Uterine and ovarian carcinoma in patient receiving gonadotrophin therapy-case report. Brf Obstet (jynaecol 1982;89:962-4.

5 Carter ME, Joyce DN. Ovarian carcinoma in a patien hyperstimulated by gonadotrophin therapy for in-vitro fertilication: a case report. I In Vitro Fert Embryo Transfer 1987;4:126-8.

6 Laing RW, Glaser MG, Barrett GS. A case report of breast carcinoma in association with in-vitro fertilisation. $\mathcal{J} R$ So Med 1989;82:503

7 Cowan LD, Gordis L, Tonascia JA, et al. Breast cance incidence in women with a history of progesterone deficiency. Am f Epidemiol 1981;114:209-17.

8 Coulan $\mathrm{CB}$, Annergers JF. Chronic anovulation may increase postmenopausal breast cancer risk. FAMA 1983;249:445-6.

9 Hull MGR. Epidemiology of infertility and polycystic ovarian disease: endocrinological and demographic sudies. Gynecology and Endocrinology 1988;1:235-42.

10 Adams J, Polson DW, Franks S. The prevalence of polycystic ovaries in women with anovulation and idiopathic hirsutism. ovaries in women with an
$B r$ Med 7 1986;293:355-9.

11 Chamlian DL, Taylor HB. Endometrial hyperplasia in young women. Obstet Gynecol 1970;36:659-66.

12 Babaknia A, Calfopoulos P, Jones HW. The Stein-Leventhat syndrome and coincidental ovarian tumours. Obstet Gynecol 1976;47:223-4

13 Alderson M. Parity and breast cancer. Br Med J 1981;283 9-12.

\section{Abortion debate}

SIR,-Dr Tony Delamothe's summary of the abortion debate ${ }^{1}$ and $\mathrm{Mr}$ John M McGarry's earlier letter on the safety of therapeutic abortion ${ }^{2}$ prompt me to offer my 20 years' experience as a hospital chaplain and parish priest of the consequences of abortion

About $80 \%$ of people I see are those 
with arrested grief syndrome three to five years after abortion. In two cases the women had had abortions more than 10 years before. Occasionally fathers and siblings have also come for help, and they nearly always present with unexplained depression, which comes to a climax at the same time each year, during which they have felt suicidal.

In all cases considerable improvement has been achieved after some form of "ritual mourning." This has enabled the grief to be released together with feelings of self judgment and anger. This anger has often been directed towards the medical profession and counsellors, whom the mourners perceive as having let them down by their attitude and by using semantics and technical jargon, which is designed to reduce the impact of the action taken. Most, if not all, patients have said that they would have preferred the truth about what was involved, including the pain of grief they would suffer, because they would have been able to ask more quickly for help from their social worker and hospital chaplain or parish priest.

In my view there is a growing need for fuller cooperation between all the disciplines at both hospital and community levels to tackle the increasing problem of arrested grief syndrome after abortion.

Praze-an-Beeble,

Cornwall TR1+0LL

I Delamothe T. Abortion debate. Br. Med f 1989;299:814-6. 30 September.

McGarry JM. Twenty one years of legal abortion. Br Med 1989;299:261. (22 July.)

\section{Repetitive strain disorder}

SIR, - Mr Nicholas Barton's perverse editorial serves to remind us of how the prejudiced attitudes of some members of the medical profession can exacerbate the harm caused by hazardous substances, environments, and processes in the workplace.

Workers do not welcome repetitive strain disorders as a potential supplement to their income; most sufferers receive no compensation. Most repetitive strain disorders are not scheduled as prescribed industrial diseases; even when a disease is listed the $14 \%$ disability qualification rules out most claims. Only four of the 91 workers found to be suffering from tenosynovitis by special medical boards in 1986-7 were deemed "sufficiently" disabled to receive disablement benefit. ${ }^{2}$ Common law compensation is not there for the taking either. The onus is on the worker to prove both negligence on the part of the employer and that "reasonably practicable" precautions would have prevented the disease. Employers have to step a long way out of line to escape the absolution from all guilt bestowed by the words reasonably practicable.

Mr Barton would do well to read some of the more objective articles in the British fournal of Industrial Medicine. Waldron's assertion that many cases of tenosynovitis go unrecorded because workers "do not bring it to medical attention and certainly not to the attention of their managers for fear they may lose their jobs" is borne out by our experience in the subject of occupational health over the past decade. We see that things are similar for all occupational disorders. Workers are either unaware or too scared of the consequences to claim compensation. A royal commission found that fewer than $10 \%$ of workers eligible for compensation actually claimed.

The decline in the number of compensation claims in Australia does not represent the derailment of the compensation gravy train. It represents the occurrence of fewer cases of repetitive strain disorders as a result of a much greater emphasis on ergonomic design of work stations and processes.
Unlike Mr Barton, Waldron lays the blame not with the worker, but with the medical profession. "It is surely not to the credit of occupational medicine that a condition that has been known about for so many years is still so common and regarded as a minor nuisance rather than the serious condition it really is." That doctors routinely misdiagnose a range of repetitive strain disorders is beyond doubt. To assume that they do this as a result of the hectoring of greedy workers seems strange. A system of medical training that ignores occupational ill health, excepting a few lectures on such clinical entities as "malingering," "absenteeism," and "compensation neurosis," is where the real problem lies. Although we agree that simple measures are required to address the root cause of repetitive strain disorders-that is, designing the workplace to suit the workersimple measures will never be effected while the likes of Mr Barton let negligent employers off the hook.

RORY O'NEILL

Sheffield Occupational Health Project, JULIA HASELDINE

\section{Birlev Moor Health Centre,}

Sheffield S124QN

1 Barton N. Repetitive strain disorder. Br Med f 1989;299:405-6. (12 August.)

2 Department of Employment. Health and Safety Statistics 1986-7. Employment Gazette [Occasional Supplement No 1] 1989;97 (No 2)

3 Waldron HA. Anyone for teno? Br f Ind Med 1987;44:793-4.

4 Pearson Commission. Report of the Roval Commission on civil liability and compensation for personal inquiry. London: liability and
HMSO, 1978.

5 Anonymous. Occupational hazards in hospitals: risk of infection [Editorial]. Brf Ind Med 1987;44:433-4.

AUTHORS' REPLY, - Any worthwhile opinion on the subject of my editorial must be based on experience, and different types of specialists encounter the problem in different ways. Mr Rory O'Neill and Ms Julia Haseldine do not explain the nature of their work or experience, but I am quite prepared to accept their assertion that many workers with possible repetitive strain disorders do not make claims in connection with them. I hope that they will accept my assurance that hand surgeons are increasingly swamped by patients making just such claims and that lawsuits about them, far from being rare, are extremely common.

Mr O'Neill and Ms Haseldine recommend me to read Dr Waldron's paper, which I have done with interest. May $I$, in return, suggest that they should read my editorial, as they seem to have read only a small part of it. They have taken such offence at my opinion that some workers are climbing on a bandwagon that they have overlooked its context and the rest of the editorial. I specifically said that I believe that this is the least common group. They are convinced that many workers suffer from repetitive strain disorders; I said that. They state that the decrease in claims in Australia is due to greater use of ergonomic principles; I recommend this. They say that I let negligent employers off the hook; I did not do that: on the contrary, I said that it is right and proper that trade unions should protect the interests of their members. I also said that employers naturally resist this, but that does not mean that I necessarily support them in doing so. It would be as foolish to think that employers are always right as to suppose (as Mr O'Neill and Ms Haseldine apparently do) that the worker is always right. Sometimes the condition is caused by the job, and sometimes it is not. The duty of the doctors is to provide an unbiased opinion and what help they can. $\mathrm{Mr}$ O'Neill and Ms Haseldine say that I "blame the worker." I blame nobody: my concern is not with blame but with cure.

Such inaccuracy and bias are unfortunately all too typical of much discussion on this difficult subject. I, like other specialists who try to treat these patients and like the many people who have expressed agreement with my editorial, are distressed that we are often unable to relieve their symptoms. As a doctor, that is what I want to do. Patients will not be helped by unsupported allegations, unscientific attitudes, or emotional reactions. Occupational medicine is an important subject and must not be brought into disrepute by this sort of thing. The purpose of my editorial was to encourage a more objective, accurate, and scientific approach.

Queen's Medical Centre,

NICHOLAS BARTON Nottingham NG7 2UH

\section{Improving clinical effectiveness in the NHS}

SIR,-In her NHS review article Lois Quam' clearly identifies that the emphasis in the white paper Working for Patients ${ }^{2}$ is on efficiency and not effectiveness of clinical care and that the white paper's interpretation of quality relates to patient satisfaction and hotel services. She argues for a model of clinical effectiveness with sound reasoning as to how it could reform clinical practice and improve health care but believes that "this clinical effectiveness approach and the white paper are incompatible avenues of reform."

This need not be so if the potentially important new roles of the health authorities under the white paper's proposals are recognised. The health authorities will have to determine the population's health needs and commission health services to match these needs and monitor whether this is being achieved. Large areas of the white paper are still open to interpretation. It would be possible with a strengthened commissioning role to bring clinical effectiveness into specified quality measures. Currently routine measures of patient outcome are lacking, and it is here that research must be supported and resources directed.

Resource management initiatives, together with case mix computer systems and diagnostic related groups, lay the foundations for medical audit and clinical outcome measures. They should be implemented not by managers interested only in efficiency and cost but by those concerned with both management and clinical practice and interested in clinical effectiveness. Clinicians' participation allows clinical feedback, the importance of which in improving clinical quality has already been recognised." Access to data, its ownership, and its interpretation have not yet been seriously addressed. If the white paper is not intended to allow a provider led service and the new commissioning authority roles are to be taken seriously both providers and commissioners must have access to the data and be able to interrogate and interpret it to monitor the standards of efficiency, effectiveness, and quality, as well as costs, as laid down in the contract.

Working for Patients lays the onus on the new commissioning health authorities to match services to the health needs of the populations they serve. As part of this, health authorities will have to monitor whether the defined needs are being met - that is, measure outcome (or effectiveness) of the health care provided. This thinking is still in its infancy. Although Ms Quam generously recognises the "strong British tradition in epidemiology," there is much development work needed both to specify health needs of a population in realistic terms appropriate for contracting purposes and to set up systems for monitoring. Duplication of expensive systems by providers and commissioners would be a nonsense. The hospital systems already identified and set up (or being set up) form part of the major database to which $\mathrm{Ms}$ Quam refers. They must form part of the overall monitoring mechanisms and hence must be accessible to commissioning authorities. 